\title{
Marine disposal of radioactive wastes
}

\author{
D. S. Woodhead \\ Ministry of Agriculture, Fisheries and Food, Fisheries Radiobiological Laboratory; \\ Hamilton Dock, Lowestoft, Suffolk, NR32 1DA, U. K.
}

\begin{abstract}
In a general sense, the main attraction of the marine environment as a repository for the wastes generated by human activities lies in the degree of dispersion and dilution which is readily attainable. However, the capacity of the oceans to receive wastes without unacceptable consequences is clearly finite and this is even more true of localized marine environments such as estuaries, coastal waters and semi-enclosed seas. Radionuclides have always been present in the marine environment and marine organisms and humans consuming marine foodstuffs have always been exposed, to some degree, to radiation from this source. The hazard associated with ionizing radiations is dependent upon the absorption of energy from the radiation field within some biological entity. Thus any disposal of radioactive wastes into the marine environment has consequences, the acceptability of which must be assessed in terms of the possible resultant increase in radiation exposure of human and aquatic populations. In the United Kingdom the primary consideration has been and remains the safe-guarding of public health. The control procedures are therefore designed to minimize as far as practicable the degree of human exposure within the overall limits recommended as acceptable by the International Commission on Radiological Protection. There are several approaches through which control could be exercised and the strengths and weaknesses of each are considered. In this review the detailed application of the critical path technique to the control of the discharge into the north-east Irish Sea from the fuel reprocessing plant at Windscale is given as a practical example. It will be further demonstrated that when human exposure is controlled in this way no significant risk attaches to the increased radiation exposure experienced by populations of marine organisms in the area.
\end{abstract}

\section{INTRODUCTION}

The potential of the sea to absorb waste matter and render it harmless has probably been known empirically from prehistoric times. Although it is likely that this potential was strained in certain localities by earlier civilisations the problem has only reached significant proportions with the development of industrialisation, the mechanisation of agriculture and the rapid growth of the human populations which could thus be supported. The magnitude of the detrimental effects of wastes is generally related to the concentrations present in the environment. Therefore the diluent and dispersive actions of tides and currents are important determinants of the capacity of a particular environment to receive a waste on a continuing basis without significant damage. For certain wastes (e. g. sewage) chemical and biological processes may convert noxious components to harmless products, or geochemical processes may act to increase the isolation of non-degradable components (e. g. heavy metals). Contrarily, these same processes may serve to reconcentrate certain materials, increasing their availability to, and potential for exposure of, marine organisms and perhaps, ultimately, man. The rational use of the 
capacity of the sea to accept waste without unacceptable environmental or human consequences therefore requires considerable understanding of the interactions of the waste with all components of the marine environment.

The damaging effects of radioactivity result from the absorption in living tissue of the radiation energy emitted during decay, and this hazard was recognised soon after the discovery of radioactivity at the end of the 19 th century. The rapid adoption of radiation by the medical profession as a diagnostic and therapeutic tool, despite the known hazards, had several consequences. Firstly, an increasing amount of effort was directed towards gaining an understanding of the biological effects of irradiation. Secondly, recommendations for the limitation of occupational exposure were formulated, and safety practices to achieve this, whilst still realising the benefits, were developed. Thus there was a considerable body of information and experience available for application to the radiation protection problems which arose when the commercial exploitation of the nuclear fuel cycle for electricity generation became practicable.

\section{CONSTRAINTS ON HUMAN RADIATION EXPOSURE}

The International Commission on Radiological Protection (ICRP) is the primary source of guidance in the field of radiation protection. From time to time the Commission publishes recommendations as to the fundamental principles upon which appropriate radiation protection measures can be based, and those published in 1966 (ICRP, 1966) have gained wide acceptance.

In the dose range of concern in radiological protection the Commission has adopted the cautious assumptions that any exposure to radiation carries a finite risk of the development of malignant disease or of the induction of genetic damage expressible in offspring, and that the risk is directly proportional to the accumulated dose. On this basis the objective of radiation protection is to limit the risk of damaging effects to an acceptable level while still permitting those activities which entail radiation exposure and from which benefit may be derived. At that time there was a lack of detailed information as to the precise nature of the dose-effect relationship and it was accepted

Table 1. ICRP dose limits for members of the general public

\begin{tabular}{|c|c|c|}
\hline & Organ or tissue & $\begin{array}{l}\text { Dose limit } \\
\text { (rem } \mathrm{a}^{-1} \text { ) }\end{array}$ \\
\hline \multirow[t]{6}{*}{ Individuals } & $\begin{array}{l}\text { Gonads, red bone marrow, and, in the case of uniform } \\
\text { irradiation, the whole body }\end{array}$ & 0.5 \\
\hline & Skin, bone & 3.0 \\
\hline & Thyroid, children up to $16 \mathrm{y}$ of age & 1.5 \\
\hline & Thyroid, persons over 16 y of age & 3.0 \\
\hline & Hands and forearms, feet and ankles & 7.5 \\
\hline & Other single organs & 1.5 \\
\hline Populations & Gonads & $\begin{array}{l}5 \text { rem per person } \\
\text { in } 30 \text { a averaged } \\
\text { over the whole } \\
\text { population }\end{array}$ \\
\hline
\end{tabular}


that a considerable element of judgement was involved in deciding on a degree of risk which would be considered acceptable in particular situations and also that quantitative evaluation of benefits was very difficult. Nevertheless, the Commission recommended dose limits which it considered would achieve the objectives of radiation protection, and the values for individual members of the general public are given in Table 1 . The exposure from natural background $\left(0.1-0.2 \mathrm{rem} \mathrm{a}^{-1}\right)$ and that received, as a patient, from medical procedures are specifically excluded from the dose limits and the contributions from all other sources, both internal and external to the body, are additive within the limits. In the case of internal exposure it is not possible to apply the dose limits directly. The limits have therefore been re-evaluated in terms of the concentrations of individual radionuclides in air and water which, through continuous daily intake at standard rates by a man of standard metabolism and morphology, would maintain body or organ burdens sufficient to deliver the limiting dose rates (ICRP, 1960; ICRP, 1964). The limiting concentrations in drinking water can be related by simple extension (i. e. by employing an appropriate consumption rate) to corresponding limits in individual food items. These limiting concentrations in environmental materials are known as "derived working limits."

The assumptions concerning the dose-response relationship underlying the setting of the dose limits have two important practical consequences. Since any dose, however, small, is considered to entail an associated, non-zero, risk of harm, doses should not only be kept within the recommended limits but also as far below these limits as is reasonably achievable, with due account being taken of risks, benefits and costs. In addition ${ }_{r}$ any estimate of the total radiation hazard requires, in principle, the integration of dose over the whole of the exposed population to give the collective dose in man-rem. Following the recommendations of the Commission, such an estimate would be necessary to ensure that the genetic dose limit was respected. It was also indicated that the estimate could provide a basis for the cost-benefit analysis of any procedure giving rise to radiation exposure. These considerations have been expanded and incorporated into the most recent recommendations of the Commission which also include a change in the principle employed to set the dose limits for certain specific organs and tissues (ICRP, 1977). However, the detailed consequences of this change have yet to be fully developed in terms of the derived limiting concentrations in environmental materials. Therefore the remainder of this discussion will be concerned with the application of the earlier recommendations of the Commission to the controlled disposal of radioactive wastes to the marine environment.

\section{APPROACHES TO THE CONTROL OF EXPOSURE FROM RADIOACTIVE CONTAMINATION OF THE MARINE ENVIRONMENT}

In order to apply constraints to the degree of radiation exposure of the general public within the limits as recommended by ICRP, it is clearly necessary to develop a means of relating the magnitude of the potential source of radiation to the resultant exposure. For a discharge of radioactivity into the sea, with the ensuing uncontrolled nature of the interactions between the radionuclides and the components of the environment, there are only two points at which control could possibly be applied, i. e. the point of discharge and the point of exposure. In practice the former is the only feasible option. Thus the 
amount of radioactivity discharged must be limited to the extent that no member of the general public could be exposed to doses in excess of the recommended limits. There are three approaches which have been used to achieve this objective.

\section{Point of discharge control}

This method depends upon the application of concentration limits for the radionuclides in the effluent at the point of discharge and takes account of the subsequent processes controlling their distribution in the environment in a very generalised manner (Preston, 1969; IAEA, 1978). Account is, however, taken of the relative radiotoxicities of the nuclides and the individual permissible concentrations in the discharge are generally related to the maximum drinking water concentrations recommended by ICRP for continuous occupational exposure (ICRP, 1960; ICRP, 1964).

This system of control has several superficial attractions: (a) There is a single set of maximum permissible discharge concentrations applicable to all situations; (b) it is simple for the operator to apply; and (c) monitoring procedures by regulatory authorities are straightforward. It is, however, inadequate in certain respects. Reasonable confidence that exposures in excess of the recommended limits cannot arise for any discharge may be gained only by applying rather large safety factors to the general assumptions about environmental behaviour. In a few cases these could prove to be insufficient leading to the dose limits being exceeded (Preston, 1969). Equally, the application of such large safety factors will probably result in low values for the limiting discharge concentrations and may therefore entail unjustified expenditure on effluent treatment plant in relation to the reduction in the likely radiation hazard in many situations. Estimates of the actual radiation exposure to either individuals or populations and hence assessment of the implied hazard cannot be made for any site by this method (IAEA, 1978).

\section{The specific activity approach}

This control procedure (Table 2) depends on a re-evaluation of the permissible body or organ burdens recommended by ICRP for individual radionuclides in terms of specific activities (activity of radionuclide per gram of the element) in relation to the concentrations of the corresponding stable elements in the body or organ. These specific activities then become the limiting values for the receiving water body, and provided that environmental processes do not differentially affect the different isotopes of an element, the limiting specific activity cannot be exceeded at any point in the food chain, or ultimately in the human body (Preston, 1969; Foster et al., 1971; IAEA, 1978).

The relative uniformity of the chemical composition of seawater makes this approach appear attractive for the control of discharges of liquid radioactive wastes to the marine environment since, in principle, the derived specific activities can be used to set maximum permissible concentrations for each radionuclide in seawater. The rate of introduction of radionuclides therefore needs to be set so that these concentrations (and hence specific activities) are not exceeded, a procedure which only requires information as to the natural processes of dilution and dispersion in the receiving water mass. The monitoring of discharges controlled in this manner is also straightforward, merely 
Table 2. Outline of the specific activity approach to the assessment of discharges of radioactive wastes

\begin{tabular}{|c|c|c|c|}
\hline $\begin{array}{l}\text { Organ or body burden } \\
\text { of stable element }\end{array}$ & $\begin{array}{l}\text { ICRP standard: max- } \\
\text { imum permissible or- } \\
\text { gan or body burden of } \\
\text { radionuclide } \\
\text { Maximum permis- } \\
\text { sible specific activity } \\
\text { in the organ or body } \\
\text { Maximum permis- } \\
\text { sible specific activity } \\
\text { in seawater }\end{array}$ & $\begin{array}{l}\text { Radionuclide com- } \\
\text { position of the ef- } \\
\text { fluent } \\
\text { Equilibrium water } \\
\text { concentration for unit } \\
\text { input } \\
\downarrow \\
\begin{array}{l}\text { Equilibrium specific } \\
\text { activity in seawater }\end{array} \\
\text { Environmental capac- } \\
\text { ity: maximum per- } \\
\text { missible discharge } \\
\text { rate } \\
\text { Authorised discharge } \\
\text { rate }\end{array}$ & $\begin{array}{l}\text { Hydraulic and } \\
\text { geochemical } \\
\text { data } \\
\text { Stable element } \\
\text { concentration } \\
\text { in seawater }\end{array}$ \\
\hline
\end{tabular}

requiring the analysis of water samples taken in the vicinity of the discharge for radionuclide concentrations (or perhaps a determination of specific activity).

A major shortcoming of this approach is the reliance upon the assumption that the environmental behaviour of an introduced radionuclide is an exact parallel of its stable counterpart. The majority of marine discharges of liquid radioactive wastes are to coastal waters and it is precisely here that the concentrations of trace elements and their physico-chemical form is likely to be most variable. Also the limiting situation resulting in exposure tends to occur in the immediate vicinity of the discharge where it is least probable that an introduced radionuclide is in exchange equilibrium with its stable isotopes in all the relevant compartments. A further problem arises for those elements for which there is no stable isotope, e.g. technetium, plutonium, americium, and the majority of the members of the natural decay series. Radionuclides of these elements cannot be controlled by the specific activity method. Neither is the method applicable for those radionuclides for which the gastro-intestinal tract is the critical organ for exposure since the degree of exposure depends on the quantity of the radionuclide ingested and not the specific activity in the foodstuff. In addition, an alternative procedure is necessary to ensure that excessive external exposure cannot arise from radionuclides adsorbed to sediments on beaches.

\section{Critical pathway analysis}

The deficiencies of the two previous control methoois are remedied by an analysis which treats each disposal situation separately with the objective of identifying and 
Table 3. Outline of the critical pathway approach to the assessment of discharges of radioactive wastes

Radionuclide composition of the effluent

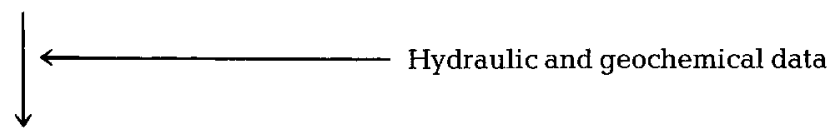

Equilibrium concentrations in water for unit input rate

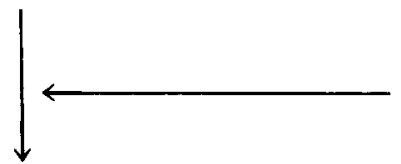

Concentration factors for environmental materials

i. e. $\frac{\mathrm{p} \mathrm{Ci} \mathrm{g}^{-1} \text { material }}{\mathrm{p} \mathrm{Ci} \mathrm{g}^{-1} \text { water }}$

Equilibrium concentrations in environmental materials

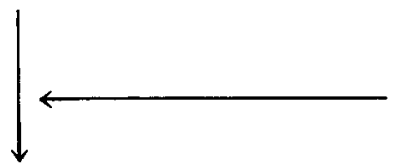

Habits survey data: seafood consumption rates, time spent on beaches etc.

Rate of exposure or intake of radionuclide

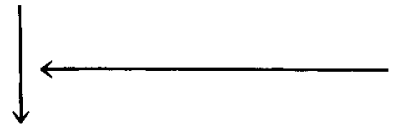

ICRP standards: exposure rate or daily intake to maintain body burden

Environmental capacity: maximum permis-

sible discharge rate

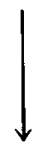

Authorised discharge rate

quantifying the routes which could potentially result in significant human exposure (Preston, 1969; Foster et al., 1971; IAEA, 1978). This approach, critical pathway analysis, is summarised in Table 3. A preliminary examination of a proposed disposal site is usually sufficient to identify the likely combinations of radionuclides and pathways which will be the most important and on which the subsequent analysis should concentrate. In order to determine the permissible discharge rate the consequences of a unit input $\left(1 \mathrm{Ci} \mathrm{d}^{-1}\right)$ are traced for each radionuclide. Site-specific hydrographic data allow the equilibrium concentrations in the receiving water mass to be predicted. These are combined with appropriate concentration factors to determine the probable concentrations of radionuclides in those components of the environment identified as being likely to engender the greatest degree of human exposure. Information concerning the consumption rates of contaminated seafoods or occupancy times of contaminated beaches can then be used to calculate the daily intakes of the radionuclides or the daily exposure. The inverse ratio of these to the appropriate maximum permissible values recommended by ICRP gives an estimate of the maximum permissible daily discharge rate or, effectively, the environmental capacity to receive the waste without unacceptable consequences. The major differences between this control method and the specific activity 
approach lie in the requirements for estimates of the degree of contamination of environmental materials and, more importantly, detailed information concerning the eating, working and leisure habits from which exposure may ensue, in either the local or a more distant population. To ensure that no member of the general public receives exposure in excess of the dose limit it is necessary to identify the individual or group of individuals who have exceptional habits leading to the highest potential degree of exposure. The estimated exposure of the critical individual in a small population or the average for the critical group in a large population then provides the basis on which the maximum permissible discharge rate is ultimately determined (Preston, 1969).

The limitation of human exposure is the prime objective of the three control procedures described. In principle, there is no reason why the limitation of the exposure of marine organisms should not be substituted as the objective provided that appropriate dose limits could be set. In practice, however, the primacy of human dose limitation is retained for the purpose of discharge control and an assessment made of the consequent exposure of marine organisms at the release rates so determined (Dunster et al., 1964).

At any disposal site the post-operational programme of environmental monitoring has two objectives. The first is to provide confirmation that the exposure via the critical pathways does not exceed the dose limits. This is normally achieved by periodic sampling and radioanalysis of the environmental materials which are directly responsible for exposure (the critical materials) and a comparison of these results with the derived working limits. In the particular case of external exposure from contaminated sediments periodic measurements of the dose rate are made. The second objective is to obtain operational data which will permit refinement of the critical pathway analyses and adjustment of the permitted discharge rates as necessary.

\section{The Windscale discharge into the north-east Irish Sea}

The storage and reprocessing of spent fuel elements is the primary activity generating low-level liquid wastes at the Windscale site (north-western Britain). The effluent contains mainly fission products together with small quantities of transuranic nuclides and traces of activation products from the fuel-element canning materials.

The early investigations of the potential hazards from the discharge of this effluent into coastal waters considered numerous pathways but it was quickly shown that there were just three which could result in significant human exposure, i. e. the accumulation of radionuclides in edible seaweed and in fish and the deposition of contaminated sediments on beaches (Dunster, 1958). Of these three pathways, that via edible seaweed was determined to be the most restrictive.

The details of the Porphyra-laverbread critical pathway are given in Table 4 and demonstrate how the environmental capacities for certain of the radiologically significant components of the waste may be determined, and the constraints which have been placed on the discharge. The data given in Column two are empirical values obtained from the post-operational monitoring programme (Jefferies, personal communication). In the initial assessment estimated values were used, based on experimental investigations of both the short-term hydrographic processes in the area (Seligman, 1955) and the concentration factors for environmental materials, leading to tentative evaluations of the environmental capacities. The resulting provisional discharge authorisations were set to 


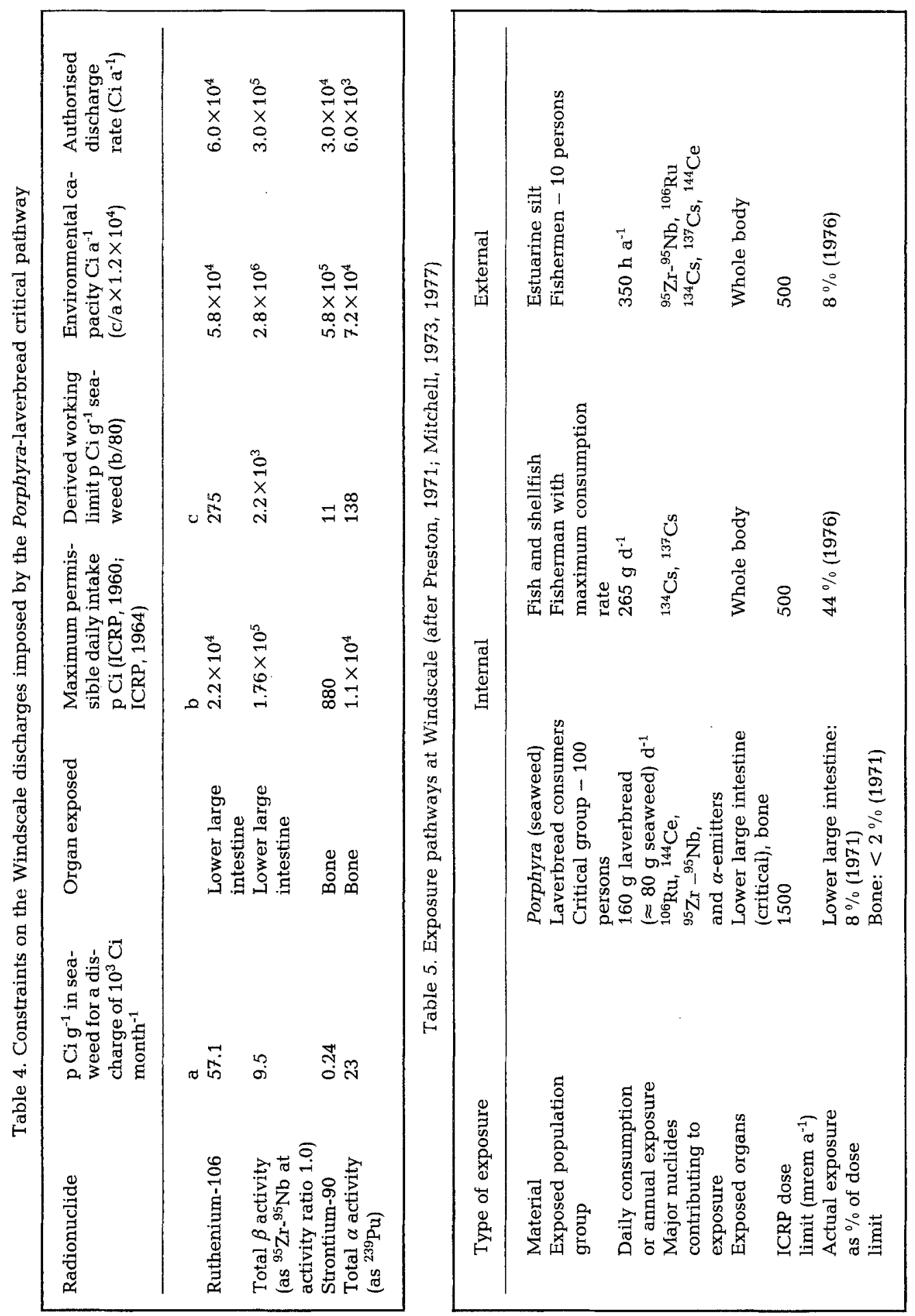


be deliberately conservative (Dunster, 1958). It is clear from Table 4 that ${ }^{106} \mathrm{Ru}$ is the critical radionuclide; however, since other radionuclides which are accumulated by Porphyra also irradiate the intestine, the total discharge cannot be the sum of the individual permissible discharges. This additivity consideration imposes a further restraint upon the discharge such that

$\frac{\mathrm{Ci}^{106} \mathrm{Ru} \text { discharged }}{15,000}+\frac{\mathrm{Ci}^{144} \mathrm{Ce} \text { discharged }}{90,000}+\frac{\mathrm{Ci} \text { total } \beta \text { discharged }}{300,000} \ngtr 1$ (Preston, 1971).

Table 5 summarizes the details of the three significant pathways present at Windscale, and also the degree of exposure due to the discharge. The environmental capacity for ${ }^{106} \mathrm{Ru}$ has been calculated on the assumption that the laverbread, as consumed, is made entirely from Porphyra of Windscale origin and the authorised discharge rate set accordingly. This provides a measure of conservatism in the assessment since it is known that weed from other sources is utilized. This factor accounts for the relatively low estimate of the actual exposure in 1971, as a percentage of the dose limit, even though the annual discharge rate was $61 \%$ of that authorised. After 1971, harvesting of Porphyra from the Windscale area ceased, and this pathway is now only of potential, rather than actual significance. In recent years the quantities of caesium radionuclides discharged have tended to increase and this is reflected in the estimated extent of exposure arising from the consumption of fish and shellfish during 1976 (Mitchell, 1973, 1977).

These factors emphasize the importance of the continuing assessment of discharges and the suitability of the critical pathway approach for the purposes of rational control.

\section{RADIATION EXPOSURE OF FISH POPULATIONS}

\section{Natural radioactivity in the marine environment}

Radioactivity has always been a factor in the marine environment and the natural radiation field from this source provides a valuable perspective for attempts to assess the significance of increases in exposure due to contaminant radionuclides. Several summaries have been made of the concentrations of the natural radionuclides in seawater, sediment and marine organisms (Mauchline \& Templeton, 1964; Woodhead, 1973a; IAEA, 1976) and of their consequent radiation exposure (Woodhead, 1973a; IAEA, 1976). A summary of the data relevant to the natural radiation exposure of marine fish is given in Table 6.

It is evident that, in seawater, the primordial radionuclide, potassium-40, is the most significant both in terms of concentration and as a source of external whole-body $\gamma$-ray exposure to pelagic organisms, representing almost $97 \%$ and $99.6 \%$ of the respective totals. For the seabed, the potassium and the uranium and thorium decay series contribute more or less equally to the $\gamma$-ray dose rate at the sediment surface and for epibenthic fish this is a more significant source of exposure than the radioactivity in the water. Of the radionuclides accumulated by fish, potassium- 40 is, once again, the principal source of whole-body irradiation and the dose rate, at $2.5 \mu \mathrm{rem} \mathrm{h}^{-1}$, will vary little between organs within a fish or between species because of the physiological requirement for and control over the concentration of this element. Other radionuclides, principally ${ }^{210} \mathrm{Po}$ and to a lesser extent ${ }^{238} \mathrm{U}$ and ${ }^{234} \mathrm{U}$ may contribute significantly to the 


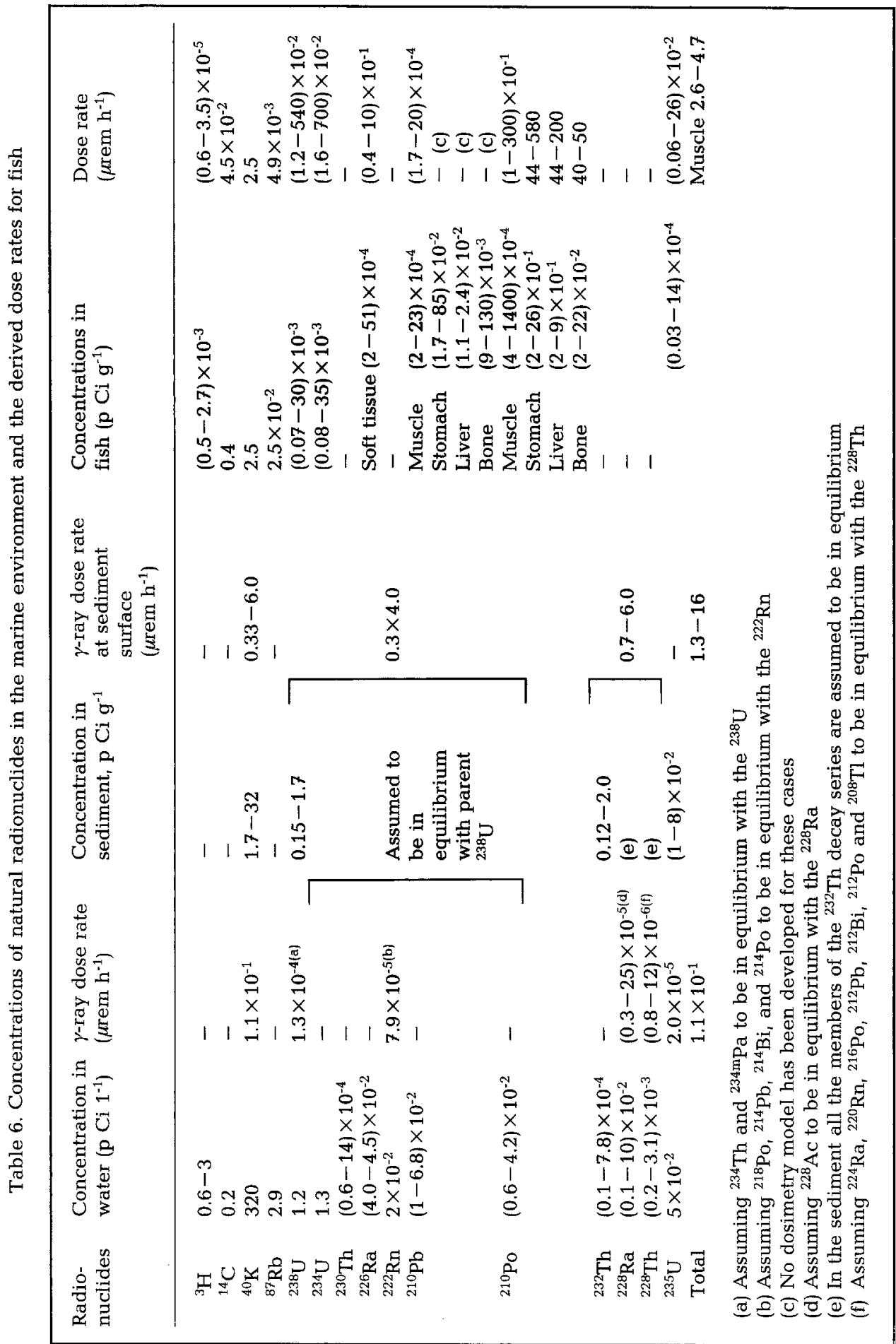


whole-body dose depending on the concentrations in tissue which are found to be very variable. In addition, ${ }^{210} \mathrm{Po}$ can deliver variable and sometimes quite high doses to specific organs e.g. stomach and liver.

Since the embryonic period is known to be relatively more radiosensitive than other stages of the fish life cycle it is also pertinent to consider the potential exposure of the developing egg. For pelagic eggs, cosmic radiation is an exposure source of variable importance depending on the position in the water column at which development takes place. The exposure rate declines from $4 \mu \mathrm{rem} \mathrm{h} \mathrm{h}^{-1}$ at the surface to $0.5 \mu \mathrm{rem} \mathrm{h}^{-1}$ at $20 \mathrm{~m}$ depth (IAEA, 1976). Potassium-40, both in the water and in the egg, is the only other significant source of exposure and for plaice eggs it has been estimated that the resultant dose rate to the developing embryo is $0.7 \mu \mathrm{rem} \mathrm{h}^{-1}$. For eggs which develop on the seabed $\gamma$-ray dose rates in the range 1-16 $\mu \mathrm{rem} \mathrm{h}^{-1}$ (see Table 6) are likely to be typical. Overall, it appears that the natural background radiation exposure of developing fish eggs is probably in the range of $1-20 \mu \mathrm{rem} \mathrm{h} \mathrm{h}^{-1}$.

\section{Contaminant radioactivity in the Windscale environment}

The first assessment of the Windscale discharge also considered the irradiation of marine organisms and indicated that the most significant source of increased exposure would be contaminated sediment. The maximum possible dose rate (at the maximum permissible discharge rate) was estimated to be about $45 \mathrm{mrem} \mathrm{h}^{-1}$ over a relatively small area and it was concluded that this would be unlikely to have any significant effect on the marine ecosystem (Dunster et al., 1964).

The degree of contamination in the immediate vicinity of the Windscale outfall is shown in Table 7, from which can be seen the potential significance of the sediment as a

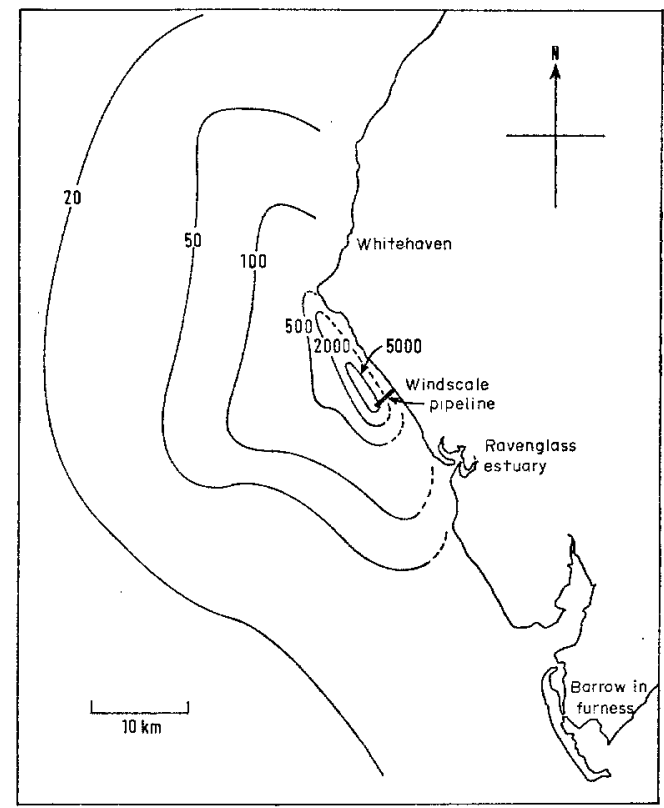

Fig. 1. Dose-rate contours on the sea bed in the vicinity of Windscale. Dose rate in $\mu \mathrm{rem} \mathrm{h}^{-1}$ 


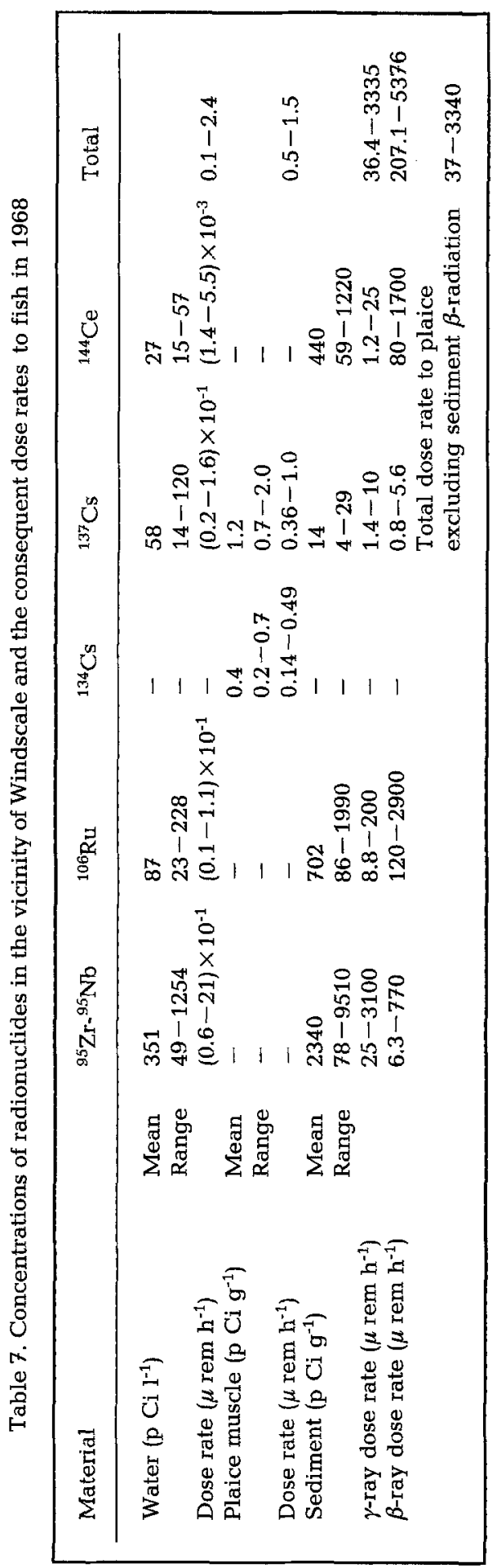




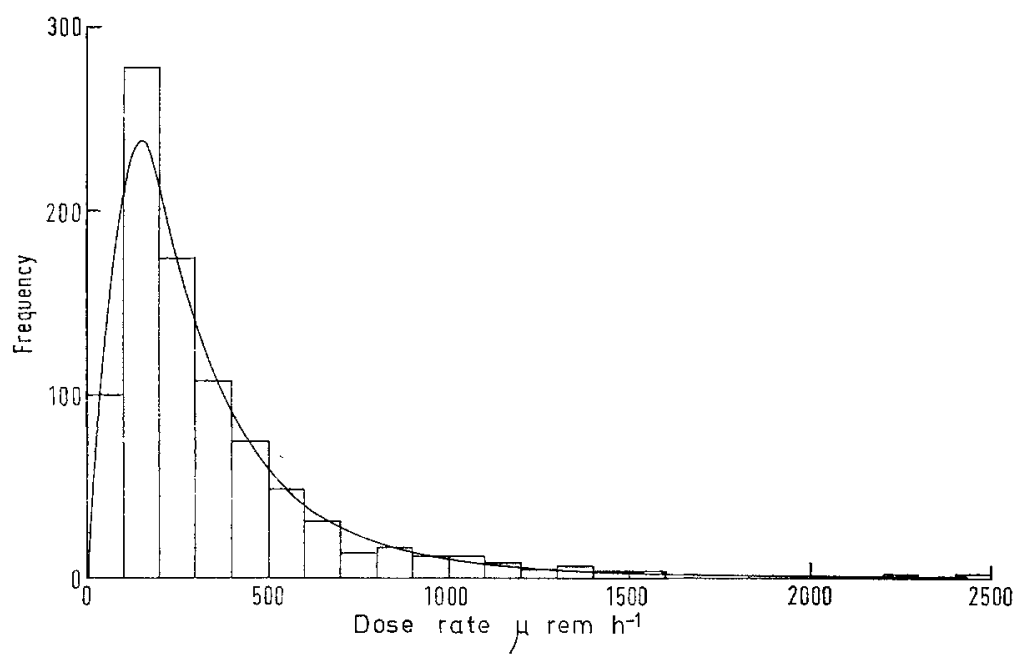

Fig. 2. Dose rate to plaice in the north-east Irish Sea as indicated by the dosimeter on the underside of the fish. The histogram represents the experimental results and the continuous curve is the best fit lognormal distribution

source of radiation. The calculation of the dose rates to fish from both internal and external sources confirms this significance for demersal fish, such as the plaice, which spend the greater part of the time very close to, or in contact with, the seabed. The results of the dosimetry calculations are given in Table 7 . Figure 1 shows the dose-rate contours at the seabed-seawater interface as calculated from measured radioactivity concentrations in sediment samples collected from a grid of 26 stations during 1968 (Woodhead, $1973 \mathrm{~b}$ ). It is apparent that the discharge results in dose rates to benthic organisms in excess of that from the natural background radiation over an area of about $2000 \mathrm{~km}^{2}$. The magnitude of the exposure of the plaice was confirmed by attaching two lithium fluoride dosimeters (one each on the upper and lower surfaces) to about 3500 fish by means of the Petersen disc tag and releasing them $0.4 \mathrm{~km}$ south of the effluent outfall. The fish were recaptured in the course of normal commercial fishing operations and returned to the laboratory. The dosimeters on the underside of the fish indicated that the mean dose rate during the time at liberty (up to $2^{1 / 2}$ years) was $350 \mu \mathrm{mem} \mathrm{h}^{-1}$ with occasional individual values up to $2.5 \mathrm{mrem} \mathrm{h}^{-1}$. The distribution of the measured dose rates is given in Figure 2. The maximum dose rates measured are of the same order as those calculated on the basis of seabed radioactivity measurements close to the discharge point. However, it is clear that the natural migrations of the fish considerably reduced the mean exposure rate in the majority of cases. The data obtained from the dosimeter on the upper surface of the fish permitted an estimate of the relative contributions from $\beta$ - and $\gamma$-radiation to be made and from this the mean dose rate to the gonads was estimated to be $250 \mu \mathrm{rem} \mathrm{h} \mathrm{h}^{-1}$. Thus the mean dose rate from the contaminant radioactivity is between 10 and 50 times higher than that to be expected from the natural radiation background.

The accumulation, by plaice eggs, of fission-product radionuclides and plutonium239 has been investigated under laboratory conditions. These data, together with the measured concentrations of the radionuclides in seawater in the plaice spawning area of 
the north-east Irish Sea, have been used to estimate the increase in radiation exposure of developing plaice embryos (Woodhead, 1970; Hetherington et al., 1976). For the fission products, the incremental dose rate, at $0.08 \mu \mathrm{rem} \mathrm{h}^{-1}$, is about $12 \%$ of that from the natural potassium-40 and a lesser proportion of the probable total natural radiation exposure, while for plutonium-239 it seems that the derived values have little meaning when the discrete and stochastic nature of the decay process is taken into account. In the case of eggs developing on the seabed, the increased exposure of the embryo due to the contaminant radioactivity could obviously be much greater, perhaps up to several mrem $\mathrm{h}^{-1}$ for a small proportion of the eggs.

\section{ASSESSMENT OF RADIATION EFFECTS IN THE NORTH-EAST IRISH SEA}

As indicated earlier in connection with human radiation protection, it is usually assumed that any exposure to radiation carries a finite risk of harm which increases in direct proportion to the total dose. Thus restrictions are applied to human exposure so that the concomitant risk is acceptably low for each individual. Although it is to be expected on this basis that increased irradiation of the biota of the north-east Irish Sea would result in detrimental somatic, teratogenic or genetic effects for a few individuals it is the preservation of marine populations which is of primary concern. If the damage to individual organisms is not manifest at the population level then the effect may be regarded as of no significance. Thus the primary consideration can be seen to be that the increased radiation exposure should not damage the overall reproductive capacity of the population.

There are rather few experimental data for fish which can usefully be used as the basis of an assessment of the effects of low-level chronic irradiation on reproductive capacity. It has recently been suggested that gametogenesis may be the most sensitive phase of the whole life-cycle. Male Oryzias latipes were exposed to tritiated water at a concentration of $10^{-2} \mathrm{Ci} \mathrm{l}^{-1}$, corresponding to an estimated whole body (or gonad) dose rate of $85 \mathrm{mrem} \mathrm{h}^{-1}$. After 10 days the normal process of spermatogenesis was found to be disrupted although signs of a recovery were apparent after 30 days (Hyodo-Taguchi \& Egami, 1977). At the higher concentration of $5 \times 10^{-2} \mathrm{Ci}^{-1}\left(420 \mathrm{mrem} \mathrm{h}^{-1}\right)$, the effect was still present after 30 days. Exposure of pairs of guppies (Poecilia reticulata) at a mean dose rate of $170 \mathrm{mrem} \mathrm{h}^{-1}$ from the age 0-3 days until the end of their breeding life produced significant effects on several aspects of breeding performance. In total, the mean lifetime fecundity (young per pair) was reduced by $43 \%$, mainly as a result of a greater incidence of temporary infertility and earlier onset of permanent sterility (Woodhead, 1977). Chronic $\gamma$-irradiation of chinook salmon eggs (Oncorhyncus tshawytscha) during the 80-day incubation period had no significant effect on the length and weight of fry at 90 days of age, return of mature fish to the hatchery, gonad development or fertility until the dose rate exceeded $210 \mathrm{mrem} \mathrm{h}^{-1}$ (Hershberger et al., 1978). A comprehensive review of the greater part of the earlier literature pertaining to radiation effects in teleost fish has recently been published (IAEA, 1976). It was concluded that the lowest dose rate at which minor radiation-induced disturbances of physiology or metabolism might be detectable in fish is of the order of $40 \mathrm{mrem} \mathrm{h}^{-1}$.

Thus it appears that the dose rates calculated for, and measured in, the marine environment at Windscale are at least an order of magnitude below those which would 
be expected to elicit any effect under controlled laboratory conditions and almost two orders of magnitude less than those necessary to have an effect on the components of reproductive capacity.

\section{LITERATURE CITED}

Dunster, H. J., 1958. The disposal of radioactive liquid wastes into coastal waters. In: Proceedings of the Second United Nations International Conference on the Peaceful Uses of Atomic Energy. 18: Waste treatment and environmental aspects of atomic energy. United Nations, Geneva, 390-399.

Dunster, H. J., Garner, R. J., Howells, H. \& Wix, L. F. U., 1964. Environmental monitoring associated with the discharge of low activity radioactive waste from Windscale Works to the Irish Sea. HIth Phys. 10, 353-362.

Foster, R. F., Ophel, I. L. \& Preston, A., 1971. Evaluation of human radiation exposure. In: Radioactivity in the marine environment. National Academy of Sciences, Washington, 240-260.

Hershberger, W. K., Bonham, K. \& Donaldson, L. R., 1978. Chronic exposure of chinook salmon eggs and alevins to gamma irradiation: effects on their return to freshwater as adults. - Trans. Am. Fish. Soc. 107, 622-631.

Hetherington, J. A., Jefferies, D. F., Mitchell, N. T., Pentreath, R. J. \& Woodhead, D. S., 1976. Environmental and public health consequences of the controlled disposal of transuranic elements to the marine environment. In: Transuranium nuclides in the environment. IAEA Symposium, San Francisco, 17-21 November 1975. IAEA, Vienna, 139-153.

Hyodo-Taguchi, Y. \& Egami, N., 1977. Damage to spermatogenic cells in fish kept in tritiated water. - Radiat. Res. 71, 641-652.

IAEA, 1976. Effects of ionizing radiation on aquatic organisms and ecosystems. - Tech. Rep. Ser. IAEA 172, 1-131.

IAEA, 1978. Principles for establishing limits for the release of radioactive materials into the environment. - Saf. Ser., IAEA 45, 1-91.

ICRP, 1960. Report of Committee II on Permissible Dose for Internal Radiation. - Int. Commn on radiol. Protect. Publ. 2, 1-233.

ICRP, 1964. Recommendations of the International Commission on Radiological Protection (As amended 1959 and revised 1962). - Int. Commn radiol Protect. Publ. 6, 1-70.

ICRP, 1966. Recommendations of the International Commission on Radiological Protection (Adopted 17 September, 1965). - Int. Commn radiol. Protect. Publ. 9, 1-27.

ICRP, 1977. Recommendations of the International Commission on Radiological Protection (Adopted 17 January, 1977), - Ann. int. Commn radiol. Protect. 1 (3), 1-53. (Zugl.: Int. Commn radiol. Protect. Publ. 26.)

Mauchline, J. \& Templeton, W. L., 1964. Artificial and natural radioisotopes in the marine environment. - Oceanogr. mar. Biol. 2, 229-279.

Mitchell, N. T., 1973. Radioactivity in surface and coastal waters of the British Isles, 1971. - Tech. Rep. Fish. radiobiol. Lab., Lowestoft 9, 1-34.

Mitchell, N. T., 1977. Radioactivity in surface and coastal waters of the British Isles, 1976. Part I: The Irish Sea and its environs. - Tech. Rep. Fish. radiobiol. Lab., Lowestoft 13, 1-13.

Preston, A., 1969. Aquatic monitoring programmes. In: Environmental contamination by radioactive materials. IAEA Symposium, Vienna, 24-28 March 1969. IAEA, Vienna, 309-324.

Preston, A., 1971. The United Kingdom approach to the application of ICRP standards to the controlled disposal of radioactive waste resulting from nuclear power programs. In: Environmental aspects of nuclear power stations. IAEA Symposium, New York, 10-14 August 1970. IAEA, Vienna, 147-157.

Seligman, H., 1955. The discharge of radioactive waste products into the Irish Sea. Part I. First experiments for the study of movement and dilution of released dye in the sea. In: Proceedings of the International Conference on the Peaceful Uses of Atomic Energy. United Nations, Geneva, 9, 701-711.

Woodhead, D. S., 1970 . The assessment of the radiation dose to developing fish embryos due to the accumulation of radioactivity by the egg. - Radiat. Res. 43, 582-597. 
Woodhead, D. S., 1973a. Levels of radioactivity in the marine environment and the dose commitment to marine organisms. In: Radioactive contamination of the marine environment. IAEA Symposium, Seattle, 10-14 July 1972. IAEA, Vienna, 499-525.

Woodhead, D. S., 1973b. The radiation dose received by plaice (Pleuronectes platessa) from the waste discharged into the north-east Irish Sea from the fuel reprocessing plant at Windscale. Hlth Phys. 25, 115-121.

Woodhead, D. S., 1977. The effects of chronic irradiation on the breeding performance of the guppy, Poecilia reticulata (Osteichthyes: Teleostei). - Int. J. Radiat. Biol. 32, 1-22. 